\title{
Methodology of hydrogen embrittlement study of long-term operated natural gas distribution pipeline steels caused by hydrogen transport
}

Hryhoriy Nykyforchyn, Olha Zvirko, Myroslava Hredil, Halyna Krechkovska, Oleksandr Tsyrulnyk, Oleksandra Student

Karpenko Physico-Mechanical Institute of the National Academy of Sciences of Ukraine, Lviv, Ukraine bnykyforchyn@gmail.com, bttp://orcid.org/0000-0003-1012-2901

olha.2virko@gmail.com, bttps://orcid.org/0000-0002-6973-6804

mysya.lviv@gmail.com, bttps://orcid.org/0000-0001-5070-8259

krechkovskahalyna@gmail.com, bttps://orcid.org/0000-0001-7392-7753

otsyrulnyk@gmail.com, bttps://orcid.org/0000-0001-9038-966X

oleksandrastudent1@gmail.com, bttps://orcid.org/0000-0002-5638-2744

Leonid Unigovskyi

Naftogazbudinformatyka Ltd., Kyiv, Ukraine

unileonid2@gmail.com

\begin{abstract}
A methodology of experimental research on hydrogen embrittlement of pipe carbon steels due to the transportation of hydrogen or its mixture with natural gas by a long-term operated gas distribution network is presented. The importance of comparative assessments of the steel in the as-received and operated states basing on the properties that characterize plasticity, resistance to brittle fracture and hydrogen assisted cracking is accentuated. Two main methodological peculiarities are pointed out, (i) testing specimens should be cut out in the transverse direction relative to the pipe axis; (ii) strength and plasticity characteristics should be determined using flat tensile specimens with the smallest possible thickness of the working part. The determination of hydrogen concentration in metal, metallographic and fractographic analyses have been supplemented the study. The effectiveness of the proposed methodology has been illustrated by the example of the steel research after its 52 -year operation.
\end{abstract}

KEYWORDS. Exiting natural gas distribution network; Pipeline steel; Hydrogen transportation; Hydrogen embrittlement; Dissipated microdamaging.

\section{OPEN ACCESS}

Citation: Nykyforchyn, H., Zvirko, O., Hredil, M., Krechkovska, H., Tsyrulnyk, O., Student, O., Unigovskyi, L., Methodology of hydrogen embrittlement study of long-term operated natural gas distribution pipeline steels caused by hydrogen transport, Frattura ed Integrità Strutturale, 59 (2022) 396-404.

Received: 13.10.2021

Accepted: 17.11.2021

Published: 01.01.2022

Copyright: (C) 2022 This is an open access article under the terms of the CC-BY 4.0, which permits unrestricted use, distribution, and reproduction in any medium, provided the original author and source are credited. 


\section{INTRODUCTION}

$\mathrm{E}$

nvironmental challenges are a global problem, and attention to these has become especially acute in recent years. One of the ways to minimize environmental challenges is considered to be a radical modernization of energy policy, in particular, by decarbonizing energy sources. This implies the use of hydrogen as an environmentfriendly fuel; therefore, the problem has been arising to transport hydrogen from potential places of its production to consumption places. To solve this task, the possibility of using the existing gas pipeline networks (both transmission and distribution) is considered [1-6]. At the first stages, a mixture of natural gas with a certain percentage of hydrogen is expected to transport. In different EU countries the maximum blend level of hydrogen in natural gas infrastructure is currently in the range $0-12 \%$ [4].

Hydrogen transportation by gas pipelines is a complex problem, in which a particularly important aspect is the possible integrity violation of the pipes due to the well-known detrimental effect of hydrogen on the mechanical properties of steels. Investigations of influence of natural gas/hydrogen mixtures on mechanical properties of pipeline steels demonstrate their susceptibility to hydrogen-induced embrittlement, which increases with the hydrogen partial pressure increasing [3]. Added hydrogen significantly influences on deterioration of mechanical properties of notched specimens [3,5].

It should be noted that hydrogen embrittlement in pipes is considered mainly due to a possible hydrogenating effect of the soil environment in the case of insulation cover damages [7-11], whereas less attention is paid to corrosion processes on the pipe inner surface, however, these could also serve as factors of pipe integrity violation [12-15]. The main issue is possible hydrogenation of the pipe wall from its inner surface because of humidity of the transported gas which causes electrochemical processes leading to hydrogen evolution [16, 17]. Hydrogen transportation by pipelines is assumed to intensify the metal hydrogenation for two reasons: (i) due to hydrogen dissociative adsorption [18] and (ii) an increase in the amount of electrochemically formed hydrogen [19] absorbed by the pipe wall.

On the other hand, gas pipeline networks usually have been operating for a long time, which leads to the essential deterioration of initial (as-received) physico-mechanical properties of steels, mostly affecting their brittle fracture resistance [20-26]. In the case of hydrogen transportation, a decrease in the resistance to hydrogen embrittlement is especially important since it can cause hardly predictable pipeline failures [19, 20, 27].

Developing the study [6], this work presents a set of experimental techniques adapted to assessing the technical state of long-term operated steels of distribution gas pipelines for hydrogen transport in a mixture with natural gas. A carbon pipeline steel after 52-year operation was investigated using the proposed methodology.

\section{MATERIALS AND METHODS}

7 he object of research is carbon steel (Ukrainian code is VST3ps) of distribution gas pipelines with an outer diameter of $159 \mathrm{~mm}$ and a pipe wall thickness of $4.5 \mathrm{~mm}$ made of rolled steel. The steel in the as-received state (spare pipes) and after 52 years of operation has been tested. The chemical composition of the steel in both states is presented in Table 1 . Note a relatively low Si content in the operated steel that can affect its quality.

\begin{tabular}{ccccccccc}
\hline Elements (wt.\%) & $\mathrm{C}$ & $\mathrm{Si}$ & $\mathrm{Mn}$ & $\mathrm{Cr}$ & $\mathrm{Ni}$ & $\mathrm{Cu}$ & $\mathrm{P}$ & $\mathrm{S}$ \\
As-received steel & 0.12 & 0.006 & 0.36 & 0.04 & 0.01 & 0.01 & 0.036 & 0.034 \\
After operation & 0.11 & 0.001 & 0.45 & 0.03 & 0.02 & 0.02 & 0.047 & 0.055 \\
\hline
\end{tabular}

Table 1: Chemical composition of the carbon steel in the as-received state and after operation.

Metallography using SEM EVO-40XVP revealed ferrite-pearlite microstructure of the tested steel (Fig. 1). Cementite precipitation at the ferrite grain boundaries and an essential amount of traces from non-metallic inclusions (max. $2 \mu \mathrm{m}$ in size) was noted in the as-received steel, and in the case of the operated steel - some cracking at the boundaries of small ferrite grains.

Standard mechanical properties of strength $\left(\sigma_{U T S}, \sigma_{Y}\right)$ and plasticity (elongation, reduction in area $(R A)$ were determined by tensile testing $\left(\varepsilon=3 \times 10^{-4} \mathrm{~s}^{-1}\right)$ using flat specimens, and impact toughness KCV by Charpy testing. Besides these tests, the effect of preliminary hydrogenation on steel's strength and plasticity was evaluated. 




(a)

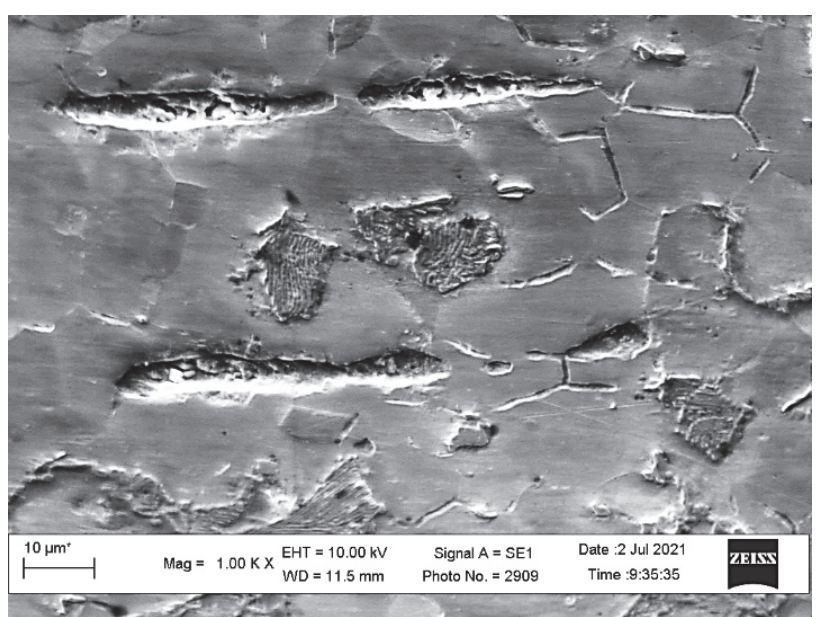

(b)

Figure 1: Microstructure of the carbon steel in the as-received (a) and operated (b) states.

Two main methodical peculiarities should be distinguished in the preparation of the specimens; (i) all specimens are cut transversally to the rolling direction/pipe axis, (ii) working part thickness for the flat specimens is $2 \mathrm{~mm}$. The former one concerns with an essentially higher sensitivity of steel characteristics to operational degradation and hydrogen embrittlement determined on transversal specimens [23, 24]. This choice is explained by the fact that operational damaging of rolled steel pipes mainly consists of microdelaminations along components of the ferrite-pearlite structure and nonmetallic inclusions elongated in the rolling direction [23, 26, 28] leading to such orientation of defects. The orientation of these defects coincides with the fracture plane of transversal specimens (in contrast to longitudinal ones) facilitating the fracture processes, thus, transversal specimens are preferable for testing. This regularity is inherent not only for pipeline steels but also for metal structures of port cranes [29] and pipes of thermal power plants [30]. The latter methodical peculiarity i.e. the use of specimens with a small thickness is reasonable taking into account that steel hydrogenation in both laboratory and field (during hydrogen transportation) conditions starts from its surface.

Fig. 2 illustrates the shape of flat tensile specimens cut from a pipe in the transversal direction after having applied the manufacture procedure summarized in Fig. 3. Their thickness and width of the working part are $1.2 \mathrm{~mm}$ and $4.0 \mathrm{~mm}$ respectively. Non-working parts of the specimens are slightly thickened $(1.7 \mathrm{~mm})$ to prevent plastic deformation during loading.

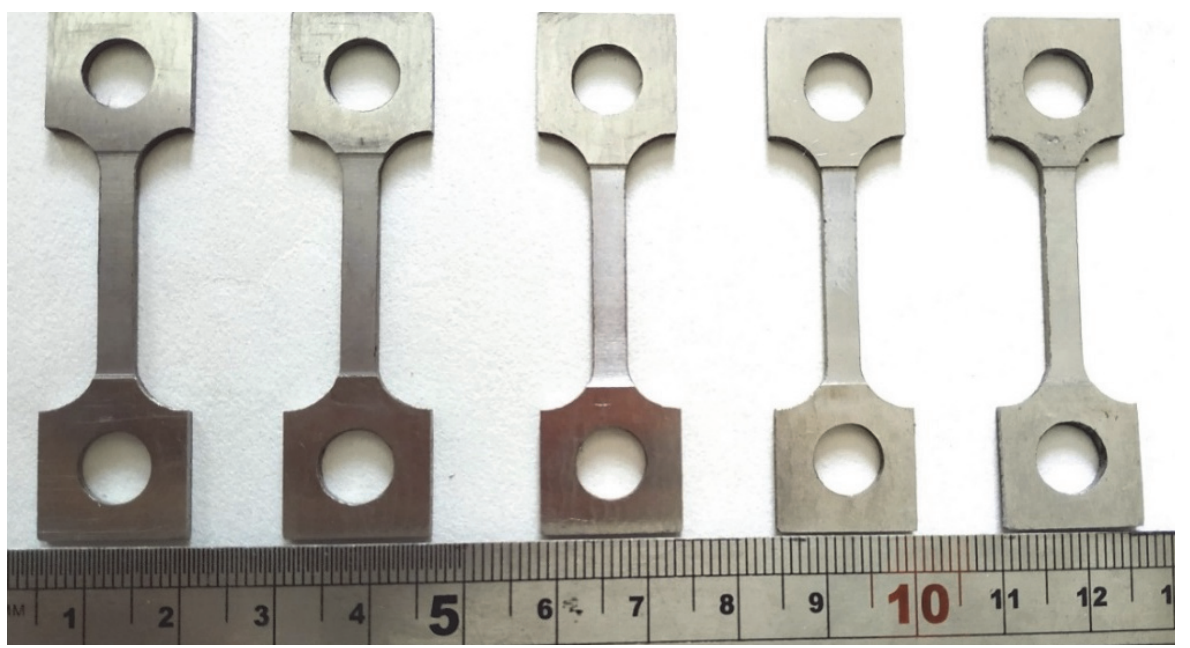

Figure 2: A set of flat tensile specimens.

The manufacture of transverse specimens for mechanical tests from thin-walled pipes became possible due to the implementation of a number of engineering solutions. Special attention was paid to tensile specimens: a workpiece in the form of a segment of the required size (Fig. 3a) was cut out from the pipe section with subsequent straightening of its 
sides (Fig. 3b), avoiding deformation of the central part, which fell on the working part of the specimen (Fig. 3c). Thanks to this procedure, a length of the straightened workpiece made it possible to manufacture the specimen of the required thickness, and the working part of such specimen did not undergo changes.

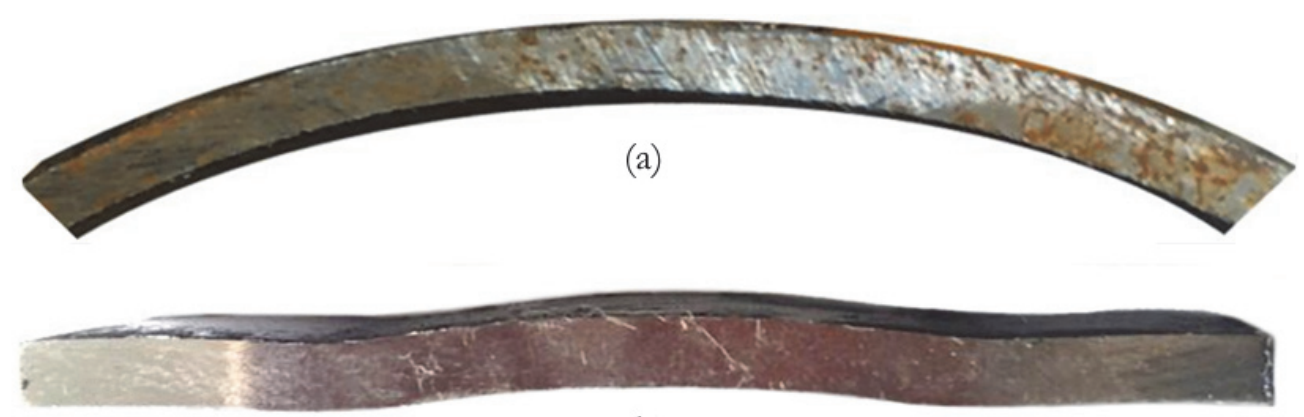

(b)

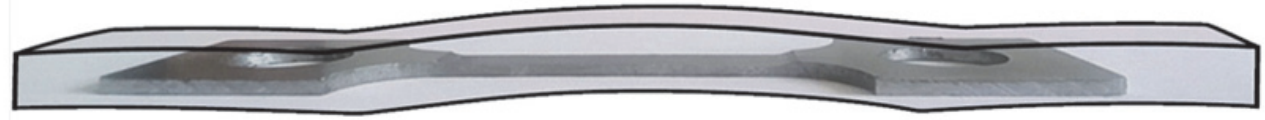

(c)

Figure 3: Fabrication steps for a flat tensile specimen.

Transversal impact specimens are segment-shaped with the pipe's radius. To ensure their fixedness during the testing, special tabs were used in which the ends of the specimens were fixed. (Fig. 4). This design made it possible to determine the impact strength of steels on specimens with a standard height of $10 \mathrm{~mm}$ and a thickness equal to the pipe wall thickness, in this case, $4.5 \mathrm{~mm}$, with a notch depth of $2 \mathrm{~mm}$.

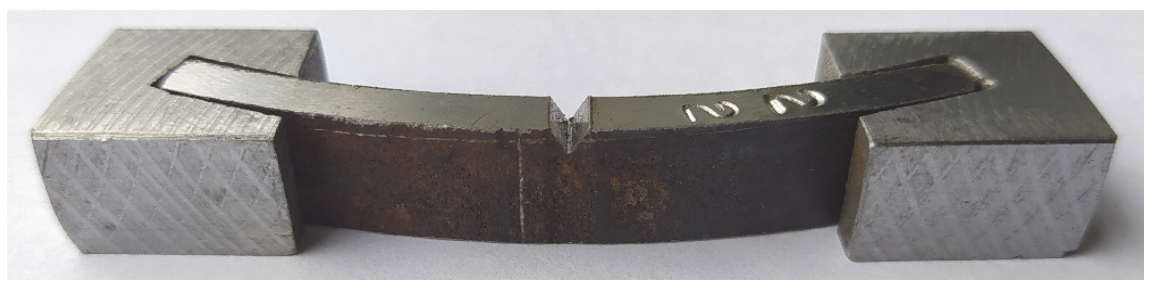

Figure 4: Specimen with tabs for the impact testing.

Susceptibility of the steel to hydrogen embrittlement was estimated by assessing the changes in characteristics $\sigma_{\mathrm{UTS}}$, $\sigma_{\mathrm{Y}}$, elongation and RA caused by specimen hydrogenation prior the tensile testing. The results are presented by the parameter $\lambda$ as the ratio of the corresponding characteristics determined for the steel in the as-received and operated states:

$$
\lambda=\frac{P-P_{H}}{P} \times 100 \%
$$

where strength and plasticity characteristics of steels are given for hydrogenated $\left(P_{H}\right)$ and non-hydrogenated $(P)$ specimens.

Preliminary hydrogenation was done electrochemically in the $\mathrm{H}_{2} \mathrm{SO}_{4}$ water solution $(\mathrm{pH}$ 3.5) under a cathodic current density of $1 \mathrm{~mA} / \mathrm{cm}^{2}$ during $100 \mathrm{~h}$. This electrolyte ensures, from the one hand, relatively low corrosion and, from the other hand, the absence of the shielding effect of surface films, which is inherent for solutions with $\mathrm{pH} \geq 4$. Prolonged hydrogenation provides the uniform distribution of hydrogen in the bulk of the specimens. After the completion of the hydrogen charging, the specimens were removed from the cell, dried, and loaded by tension in the air until fracture at the same deformation rate as the non-hydrogenated specimens. The time between the processes of hydrogenation and fracture of specimens did not exceed $10 \mathrm{~min}$, thus, the desorption of hydrogen from the metal is considered insignificant. 
The content of the residual hydrogen in steels was determined using hydrogen analyser ELTRA H-500 at temperature $950^{\circ} \mathrm{C}$. Rectangular specimens $19.0 \times 4.7 \times 4.1 \mathrm{~mm}$ were polished, degreased with acetone, and then washed with ether. Residual ether was removed with a rapid stream of hot air.

\section{ASSESSMENT OF STEEL SENSITIVITY TO HYDROGEN EMBRITTLEMENT IN THE AS-RECEIVED AND OPERATED STATES}

7 he results of tensile tests averaged from three specimens is presented in Table 2. Note a lower (by 12-15\%) strength of the operated steel comparing to the as-received one. Plasticity is relatively low as for a given steel grade, however, it was determined using transversal (T) specimens for which plasticity characteristics are expectedly lower than for longitudinal $(\mathrm{L})$ ones. In particular, as derived from [30], the ratio $\mathrm{RA}_{\mathrm{T}} / \mathrm{RA}_{\mathrm{L}} \approx 0.95$ for a lowalloyed heat-resistant steel in the as-received state and can drop to $\approx 0.85$ for the operated one due to the intensification of the steel anisotropy with operation time. For pipeline steels with clearly detectable defects oriented in the longitudinal direction, this ratio is expected to be higher. In addition, specimens of a small thickness $(1.2 \mathrm{~mm})$ were tested, which could also affect the results [31].

\begin{tabular}{|c|c|c|c|c|c|c|c|c|c|}
\hline Steel state & $\begin{array}{l}\text { Specimen } \\
\text { No. }\end{array}$ & $\sigma_{\mathrm{Y}}[\mathrm{MPa}]$ & $\begin{array}{c}\text { Average } \sigma_{\mathrm{Y}} \\
{[\mathrm{MPa}]}\end{array}$ & $\sigma_{\text {UTS }}[\mathrm{MPa}]$ & $\begin{array}{c}\text { Average } \\
\sigma_{\text {UTS }}[\mathrm{MPa}]\end{array}$ & $\begin{array}{c}\text { Elongation } \\
{[\%]}\end{array}$ & $\begin{array}{c}\text { Average } \\
\text { Elongation [\%] }\end{array}$ & $\mathrm{RA}_{\mathrm{T}}[\%]$ & $\begin{array}{r}\text { Average } \\
\text { RA }[\%]\end{array}$ \\
\hline \multirow{3}{*}{$\begin{array}{l}\text { As-received } \\
\text { steel }\end{array}$} & 1 & 330 & \multirow{3}{*}{344} & 487 & \multirow{3}{*}{468} & 18 & \multirow{3}{*}{17} & 58 & \multirow{3}{*}{59} \\
\hline & 2 & 356 & & 456 & & 14 & & 58 & \\
\hline & 3 & 345 & & 460 & & 16 & & 60 & \\
\hline \multirow{3}{*}{$\begin{array}{c}\text { After } \\
\text { operation }\end{array}$} & 4 & 303 & \multirow{3}{*}{302} & 407 & \multirow{3}{*}{404} & 15 & \multirow{3}{*}{16} & 54 & \multirow{3}{*}{54} \\
\hline & 5 & 308 & & 404 & & 16 & & 56 & \\
\hline & 6 & 296 & & 402 & & 17 & & 51 & \\
\hline
\end{tabular}

Table 2: Standard mechanical properties of steels in the as-received and operated states.

Plasticity is only slightly decreased due to operation; however, this is accompanied by strength loss, which corresponds to the main regularities of the operational degradation $[19,25,26]$ - a simultaneous decrease of both strength and plasticity indicates the development of operational microdamages in the material.

Impact testing results averaged three specimens are $(98 \pm 4) \mathrm{J} / \mathrm{cm}^{2}$ and $(9 \pm 4) \mathrm{J} / \mathrm{cm}^{2}$ respectively for the as-received and operated steel. These data indicate not only an order of magnitude difference between $\mathrm{KCV}$ values of steel in the asreceived and operated states, but also an extremely low level of brittle fracture resistance for the operated steel.

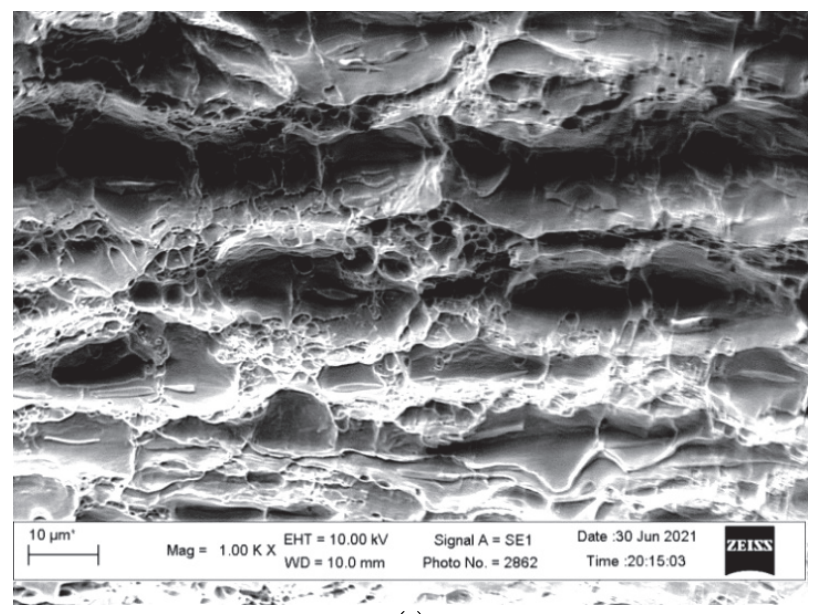

(a)

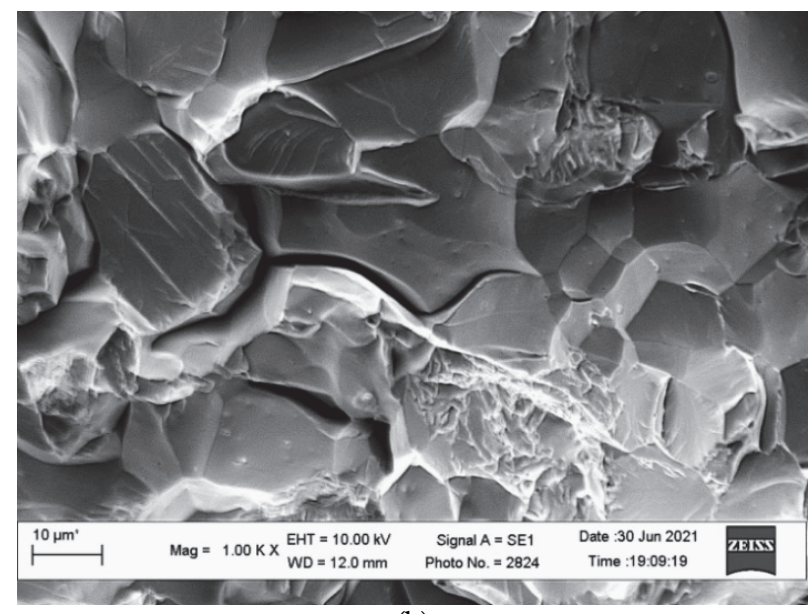

(b)

Figure 5: Fracture surfaces of impact specimens (notch on the left) of the carbon steel in the as-received steel (a) and after operation (b). 
Microfractographic analysis (Fig. 5) confirmed fundamental differences in brittle fracture resistance of steels in different states. Steel in the as-received state is characterized by more high-energy fracture type with clear signs of fracture surface texture due to delaminations along the rolling direction. Thin nonmetallic inclusions (identified as manganese sulphides by morphological features) were found, as a rule, at the bottom of delaminations oriented along the texture. Their decohesion from the matrix led to the occurrence of such delaminations. As a rule, chains of these inclusions are located in ferrite grain layers crossing their boundaries; therefore, smooth delamination surfaces were associated with fracture within the ferrite. Ridges formed as a result of the stretching of the bridges between the delaminations, with small dimples on their surface, were considered a sign of ductile fracture by micro-void coalescence within pearlite grains. Fractographic features associated with the steel texture were not observed only in the areas of brittle fracture, which correspond to the zone of spontaneous fracture in as-received steel specimens.

The main fractographic peculiarity of the operated steel is in the dominance of the cleavage fracture (Fig. $5 \mathrm{~b}$ ) that can explain its extremely low resistance to brittle fracture. Such fracture surface formation did not imply only transgranular fracture. In particular, intergranular facets were observed in some places, as well as significant secondary cracking along the grain boundaries. It should be emphasized that intergranular fracture on the fracture surfaces in the as-received steel was not detected at all. It was assumed that steel hydrogenation during long-term operation could contribute to the development of operational microdamages in the form of intergranular cracking. It is known, after all, that hydrogen promotes fracture along both the grain boundaries and interphase ones [27]. Thus, such intergranular damage was clearly visualized against the background of a predominantly transgranular relief in the zone of spontaneous fracture in the operated steel during impact testing.

Note that the extremely low impact toughness for the operated steel concerns the metal with yield strength approx. $300 \mathrm{MPa}$, whereas such $\mathrm{KCV}(\mathrm{KCU})$ value of $\sim 1 \mathrm{~J} / \mathrm{cm}^{2}$ is typical for hardened steels with martensitic structure $\left(\sigma_{\mathrm{Y}}>\right.$ $1500 \mathrm{MPa}$ ). This phenomenon can be explained only by taking into account the regularities of the operational degradation of structural steels with the intensive development of dissipated damage in the bulk of the pipe wall. Similar results on low brittle fracture resistance $\left(\mathrm{KCV} \leq 20 \mathrm{~J} / \mathrm{cm}^{2}\right)$ were reported for pipeline steels and structural steels of portal cranes [19, 29]. The results of hydrogen concentration measurements in the tested steels are presented in Table 3.

\begin{tabular}{cccc}
\hline Specimen No. & Steel state & $\begin{array}{c}\text { Hydrogen concentration } \\
\text { CH }(\mathrm{ppm})\end{array}$ & $\begin{array}{c}\text { Average } \\
\text { CH value (ppm) }\end{array}$ \\
1 & & 0.134 & 0.111 \\
2 & As-received & 0.109 & \\
3 & & 0.090 & \\
\hline 4 & & 0.818 & 0.459 \\
6 & After & 0.482 & \\
8 & operation & 0.317 & \\
9 & & 0.149 & \\
\hline 0 & & 0.656 & \\
\hline
\end{tabular}

Table 3: Hydrogen concentration in steels of different states

A significant data scattering on the hydrogen content in specimens from the operated steel is obviously due to its intense operational damage, which has an uneven character. The residual hydrogen content in the operated metal is more than 4 times higher than that of steel in the initial state. Evidently, it is the operational hydrogenation of the pipe wall that led to such an intensive operational decrease in the resistance to brittle fracture of the steel.

Figure 6 illustrates the results obtained by tensile testing of hydrogenated and non-hydrogenated specimens made of the carbon steel in different states. The mechanical properties of hydrogenated specimens were compared with the corresponding characteristics obtained for non-hydrogenated ones depending on the steel state. It can be stated that preliminary hydrogenation insignificantly affected steel strength in both as-received and operated states whereas the influence on plasticity is more noticeable.

For the plasticity characteristics, the coefficient $\lambda$ was calculated as the indicator of the hydrogen effect on steel, namely, of its susceptibility to hydrogen assisted cracking (Table 4). The obtained results indicated no effect of preliminary hydrogenation of the steel on its plasticity in the as-received state, however, the operated metal revealed high sensitivity to hydrogen action. Reduction in area is a more sensitive parameter for the assessment of hydrogen embrittlement of operated metal than elongation, which is consistent with general regularities [19, 25, 26]. However, at assessment of asreceived steels to hydrogen embrittlement, a high sensitivity of failure elongation was reported in [4]. 


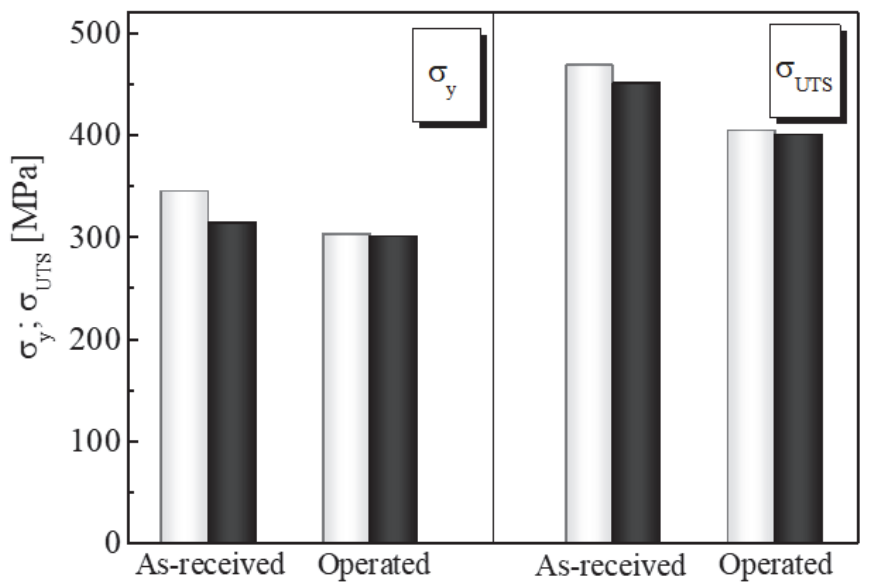

(a)

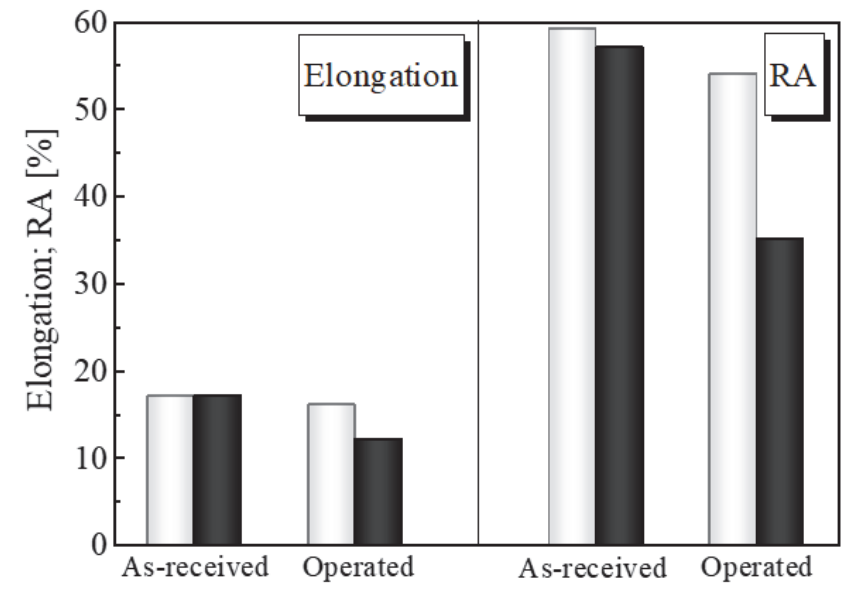

(b)

Figure 6: Strength (a) and plasticity (b) of the carbon steel under tensile testing of non-hydrogenated (white bars) and hydrogenated (black bars) specimens.

\begin{tabular}{ccc}
\hline Steel state & \multicolumn{2}{c}{$\lambda(\%)$} \\
As-received & Elongation & RA \\
After operation & 0 & 2 \\
\hline
\end{tabular}

Table 4: Assessment of metal susceptibility to hydrogen embrittlement based on plasticity characteristics.

\section{CONCLUSIONS}

7 he methodology of hydrogen embrittlement evaluation of structural steels has been adapted to the problem of a possible integrity violation of long-term operated gas pipelines in the case of transporting hydrogen or its mixture with natural gas. It implies comparative assessing the state of the as-received and operated steels based on tensile testing with the evaluation of strength and plasticity, determination of the resistance to brittle fracture (impact toughness) and hydrogen assisted cracking (tensile testing of preliminary hydrogenated specimens). The main peculiarities of the proposed methodology are: (i) the use of the specimens cut out transversally relative to the rolling direction (pipe axis), and (ii) the minimization of the plain tensile specimen thickness (in the presented case, to $1.2 \mathrm{~mm}$ ) to assess the resistance of the steel to hydrogen assisted cracking. The former peculiarity is explained by a higher sensitivity of transversal specimens to operational degradation of rolled steels as compared to longitudinal ones. Another peculiarity is due to the need to redistribute the hydrogen formed on the surface into the entire cross-section of the specimens. Some engineering solutions have been proposed to ensure these conditions for the specimens cut out from gas distribution pipelines with a small diameter and wall thickness.

The applicability of the proposed methodology for hydrogen embrittlement testing has been demonstrated by the example of the carbon steel (0.11-0.12 mass. \% of $\mathrm{C}$ ) of gas distribution pipelines in the as-received and 52-year operated states. The residual hydrogen content in the operated steel was 4 times higher than in the unoperated steel.

Operational degradation of the steel was revealed by a significant decrease in impact toughness and brittle fracture resistance. Deterioration of mechanical properties of the operated steel accompanied by high concentration of residual hydrogen was explained by intensive development of dissipated damages in the bulk of the pipe steel, which could be facilitated by the steel hydrogenation during its operation. Microfractographic studies were consistent with the results of mechanical testing on brittle fracture resistance: for the steel in the initial state, a combination of ductile fracture with delaminations in the rolling direction dominated, whereas, in the operated steel, a combination of cleavage with some elements of brittle intergranular fracture and secondary microcracking prevailed. Since intergranular cracking was not observed at all on the fracture surface of the as-received steel, it was assumed that intergranular fracture elements were the manifestation of operational damage, the appearance of which was accelerated by steel hydrogenation, and cleavage was a sign of embrittlement of the operated metal. Transgranular cleavage of the fracture surface at the stage of spontaneous 
fracture made it possible to visualize operational damage in the metal in the form of intergranular fragments visible against the background of the flat relief of the transgranular cleavage.

\section{REFERENCES}

[1] Haeseldonckx, D., and D'haeseleer, W. (2007). The use of the natural-gas pipeline infrastructure for hydrogen transport in a changing market structure, Int. J. Hydrog. Energy, 32(10-11), pp. 1381-1386.

DOI: 10.1016/j.ijhydene.2006.10.018.

[2] Vries, H., Mokhov, A.V., and Levinsky, H.B. (2017). The impact of natural gas/hydrogen mixtures on the performance of end-use equipment: Interchangeability analysis for domestic appliances, Appl. Energy, 208, pp. 10071019. DOI: $10.1016 /$ j.apenergy.2017.09.049.

[3] Meng, B., Gu, C., Zhang, L., Zhou, C., Li, X., Zhao, Y., Zheng, J., Chen, X., Han, Y. (2017). Hydrogen effects on X80 pipeline steel in high-pressure natural gas/hydrogen mixtures, Int. J. Hydrog. Energy, 42(11), pp. 7404-7412. DOI: 10.1016/j.ijhydene.2016.05.145.

[4] Pluvinage, G., Toth, L., and Capelle, J. (2021). Effects of hydrogen addition on design, maintenance and surveillance of gas networks, Processes, 9(7), 1219. DOI: 10.3390/pr9071219.

[5] Zhou, D., Li, T., Huang, D., Wu, Y., Huang, Z., Xiao, W., Wang, Q., Wang, X. (2021). The experiment study to assess the impact of hydrogen blended natural gas on the tensile properties and damage mechanism of X80 pipeline steel. Int. J. Hydrog. Energy, 46(10), pp. 7402-7414. DOI: 10.1016/j.ijhydene.2020.11.267.

[6] Nykyforchyn, H., Unigovskyi, L., Zvirko, O., Tsyrulnyk, O., and Krechkovska, H. (2021). Pipeline durability and integrity issues at hydrogen transport via natural gas distribution network, Procedia Struct. Integr., 33, pp. 646-651. DOI: $10.1016 / j . p r o s t r .2021 .10 .071$.

[7] Kim, C., Kim, W., and Kho, Y. (2002). The effects of hydrogen embrittlement by cathodic protection on the CTOD of buried natural gas pipeline, Met. Mater. Int., 8, pp. 197-202. DOI: 10.1007/BF03027018.

[8] Shipilov, S. A., and May, I. L. (2006). Structural integrity of aging buried pipelines having cathodic protection, Eng. Fail. Anal., 13, pp. 1159-1176. DOI: 10.1016/j.engfailanal.2005.07.008.

[9] Bueno, A.H.S., Castro, B.B., and Ponciano, J.A.C. (2008). Assessment of stress corrosion cracking and hydrogen embrittlement susceptibility of buried pipeline steels, Environment-Induced Cracking of Materials, 2, pp. 313-322. DOI: 10.1016/B978-008044635-6.50068-6.

[10] Cabrini, M., Lorenzi, S., Marcassoli, P., and Pastore, T. (2011). Hydrogen embrittlement behavior of HSLA line pipe steel under cathodic protection. Corros. Reviews, 29(5-6) pp. 261-274. DOI: 10.1515/CORRREV.2011.009.

[11] Voloshyn, V. A., Zvirko, O. I., Sydor, P. Ya. (2015). Influence of the compositions of neutral soil media on the corrosion cracking of pipe steel, Mater. Sci., 50(5), pp. 671-675. DOI: 10.1007/BF03027018.

[12].Askaria, M., Aliofkhazraeia, M., and Afroukhteh, S. (2019). A comprehensive review on internal corrosion and cracking of oil and gas pipelines, J. Nat. Gas Sci. Eng., 71, 102971. DOI: 10.1016/j.jngse.2019.102971.

[13] Hredil, M., and Tsyrulnyk, O. (2010). Inner corrosion as a factor of in-bulk steel degradation of transit gas pipelines. Proc. of the 18th European Conference on Fracture (ECF-18), Dresden, Germany, 30.08 - 03.09. No.483.

[14] Zhao, W., Zhang, T., Wang, Y., Qiao, J., and Wang, Z. (2018). Corrosion failure mechanism of associated gas transmission pipeline. Materials 11, 1935. DOI: 10.3390/ma11101935.

[15] Zvirko, O.I., Mytsyk, A.B., Tsyrulnyk, O.T., Gabetta, G., Nykyforchyn H.M. (2017). Corrosion degradation of steel of an elbow of gas pipeline with large-scale delamination after long-term operation, Mater. Sci., 52(6), pp. 861-865.

DOI: $10.1007 / \mathrm{s} 11003-017-0032-8$.

[16] Tsyrul'nyk, O. T., Slobodyan, Z. V., Zvirko, O. I., Hredil, M. I., Nykyforchyn, H. M., and Gabetta, D. (2008). Influence of operation of Kh52 steel on corrosion processes in a model solution of gas condensate, Mater. Sci., 44(5), pp. 619-629. DOI: 10.1007/s11003-009-9138-y.

[17] Capelle, J., Dmytrakh, I., Azari, Z., Pluvinage, G. (2013). Evaluation of electrochemical hydrogen absorption in welded pipe with steel API X52. Int. J. Hydrog. Energy, 38(33), pp. 14356-14363.

DOI: 10.1016/j.ijhydene.2013.08.118.

[18] Sun, Y., Cheng, Y. F. (2021). Thermodynamics of spontaneous dissociation and dissociative adsorption of hydrogen molecules and hydrogen atom adsorption and absorption on steel under pipelining conditions, Int. J. Hydrog. Energy, 46(69), pp. 34469-34486. DOI: 10.1016/j.ijhydene.2021.07.217.

[19] Nykyforchyn, H., Zvirko, O., Dzioba, I., Krechkovska, H., Hredil, M., Tsyrulnyk, O., Student, O., Lipiec, S., Pala, R. (2021) Assessment of operational degradation of pipeline steels, Materials, 14(12), 3247. DOI: 10.3390/ma14123247. 
[20] Nechaev, Yu.S. (2008). Metallic materials for the hydrogen energy industry and main gas pipelines: complex physical problems of aging, embrittlement, and failure, Uspekhi Fizicheskikh Nauk, 51(7), pp. 681-697. DOI: 10.1070/PU2008v051n07ABEH006570.

[21] Filippov, G.A., Livanova, O.V., Chevskaya, O.N., Shabalov, I.P., 2013. Pipe steel degradation during operation and brittle failure resistance, Metallurgist, 57, pp. 612-622. DOI: 10.1007/s11015-013-9778-x.

[22] Maruschak, P., Panin, S., Danyliuk, I., Poberezhnyi, L., Pyrig, T., Bishchak, R., and Vlasov I. (2015). Structural and mechanical defects of materials of offshore and onshore main gas pipelines after long-term operation, Open Engineering 5(1), pp. 365-372. DOI: 10.1515/eng-2015-0045.

[23] Zvirko, O.I., Kret, N.V., Tsyrulnyk, O.T., and Vengrynyuk, T.P. (2018). Influence of textures of pipeline steels after operation on their brittle fracture resistance, Mater. Sci., 54(3), pp. 400-405. DOI: 10.1007/s11003-018-0198-8.

[24] Marushchak, P. O., Kret, N. V., Bishchak, R. T., and Kurnat, I. M. (2019). Influence of texture and hydrogenation on the mechanical properties and character of fracture of pipe steel, Mater. Sci., 55(3), pp. 381-385. DOI: 10.1007/s11003-019-00313-z.

[25] Degradation Assessment and Failure Prevention of Pipeline Systems. Lecture Notes in Civil Engineering; Bolzon, G., Gabetta, G., Nykyforchyn, H., (2021) Springer: Cham, Switzerland, 102, 252 p. DOI: 10.1007/978-3-030-58073-5.

[26]Zvirko, O.I., Kryzhanivskyi, E.I., Nykyforchyn, H.M., Krechkovska, H.V. (2021). Methods for the evaluation of corrosion-hydrogen degradation of steels of oil-and-gas pipelines, Mater. Sci., 56(5), pp. 585-592. DOI: $10.1007 / \mathrm{s} 11003-021-00468-8$.

[27] McMahon Jr., C.J. (2001). Hydrogen-induced intergranular fracture of steels, Eng. Fract. Mech., 68(6), pp. 773-788. DOI: 10.1016/S0013-7944(00)00124-7.

[28] Venegas V., Caleyo F., Baudin T., Espina-Hernández, J.H., and Hallen, J.M. (2011). On the role of crystallographic texture in mitigating hydrogen-induced cracking in pipeline steels, Corros. Sci., 53, pp. 4204-4212. DOI: $10.1016 /$ j.corsci.2011.08.031.

[29] Nemchuk, O.O., and Nesterov O.A. (2020). In-service brittle fracture resistance degradation of steel in a ship-toshore portal crane, Strength of Mater., 52(2), pp. 275-280. DOI: 10.1007/s11223-020-00175-w.

[30] Student, O.Z., and Krechkovs'ka, H.V. (2012). Anisotropy of the mechanical properties of degraded 15Kh1M1F steel after its operation in steam pipelines of thermal power plants, Mater. Sci., 47(5), pp. 590-597. DOI: $10.1007 / \mathrm{s} 11003-012-9432-y$.

[31] Gussev, M. N., Busby, J. T., Field, K. G., Sokolov, M. A., and Gray, S. E. (2014). Role of scale factor during tensile testing of small specimens. ASTM, Sixth Symposium on Small Specimen Test Techniques. STP 1576.

DOI: $10.1520 /$ STP157620140013. 